\title{
Uso de Animação na Educação para a Saúde de Adolescentes em Situação de Vulnerabilidade Social
}

\author{
Use of Animation in Education for Health of Adolescents in Situation of Social \\ Vulnerability
}

REZENDE, Edson José Carpintero; Doutor; Universidade do Estado de Minas Gerais edson.carpintero@gmail.com

NOGUEIRA, Karoline de Abreu; Graduanda; Universidade do Estado de Minas Gerais designdeprodutobh@gmail.com

MAIA, Marcos; Mestrando; Centro Federal de Educação Tecnológica de Minas Gerais marcosroteirista@gmail.com

\section{Resumo}

O artigo trata-se de um estudo qualitativo, cujo objetivo foi avaliar a utilização de animação como ferramenta para promover a sensibilização e a reflexão sobre o uso de drogas ilícitas, por jovens em situação de vulnerabilidade. $O$ estudo foi realizado com alunos de nove a doze anos, matriculados no ensino fundamental de uma escola pública de Contagem - MG. A primeira etapa consiste no desenvolvimento de um curta-metragem de animação que aborda o tema "educação para a saúde: drogas", com uso de elementos lúdicos. Na segunda etapa foi realizado um grupo focal com oito alunos para exibição do material elaborado. Os jovens demonstraram interesse pela narrativa apresentada, além de construir relações associativas entre o conteúdo apresentado e a proposta de sensibilização e reflexão. Através do estudo percebeu-se que o uso dessa ferramenta é eficiente para utilização a serviço da promoção da educação para a saúde direcionada aos jovens préadolescentes

Palavras Chave: Design; Animação; Educação para a Saúde.

\begin{abstract}
The article is a qualitative study, whose objective was to evaluate the use of animation as a tool to promote awareness and reflection on the use of illicit drugs by young people in situations of vulnerability. The study was carried out with students from nine to twelve years old, enrolled in elementary education at a public school in Contagem - MG. The first stage consists of the development of a short animated film that approaches the theme "health education: drugs", with the use of ludic elements. In the second stage, a focus group was carried out with eight students to watch the material. The young people showed an interest in the presented narrative, as well as to build associative relations between the presented content and the proposal of sensitization and reflection. Through the study it was noticed that the use of this tool is efficient for use in the servisse of the promotion of health education directed to young pre-adolescents.
\end{abstract}

Keywords: Design; Animation; Education for Health 


\section{Introdução}

Um dos grandes desafios para a sociedade é o alto índice de uso de substâncias ilícitas e mesmo lícitas que resultam em alterações de comportamento, principalmente por jovens em idade escolar, quadro diretamente relacionado a problemas variados como prejuízo do aprendizado, problemas de saúde entre outras consequências de graves repercussões sociais.

Conforme estudos do IBGE (2012), escolares do nono ano que já ficaram embriagados no Brasil somam 21,8\%, em Belo Horizonte são 27,1\% escolares do último ano que já usaram drogas ilícitas no Brasil somam 7,3\% em nível nacional sendo em Belo Horizonte 9,9\%.

O trabalho preventivo junto aos jovens representa, portanto, uma necessidade, em vista ao índice preocupante de uso de drogas por jovens em idade escolar. A educação para a saúde tornase, portanto, uma solução possível, capaz de informar e esclarecer os riscos envolvidos na utilização dessas substâncias.

A promoção da saúde propõe enfocar os determinantes socioambientais e econômicos, atuando sobre as condições de vida cotidianas, direcionadas ao coletivo e à defesa dos direitos sociais (SÍCOLI; NASCIMENTO, 2003).

A abordagem educativa no contexto de promoção da saúde é fundamental para a promoção da saúde (MINISTÉRIO DA SAÚDE, 2014). A educação para a saúde caracteriza-se como um processo teórico-prático que se propõe a integrar o saber científico, o saber popular e o senso comum, de forma que possibilite a interação responsável e autônoma dos sujeitos envolvidos perante a saúde no cotidiano (REIS, 2006). Esta se preocupa em compor um serviço que prime por um modelo baseado em referenciais sociais, humanistas, culturais e ambientais. Uma das fases da vida onde os conceitos de educação para a saúde são consolidados é a adolescência. Por suas características singulares e de caráter determinante na formação do indivíduo este período mostra-se crítico, por isso é que nesse período de crise comumente as drogas se inserem em suas vidas (ZUGE e BRUM 2010; OMS, 1995; CAVALCANTE et al., 2008).

A prevenção tem se mostrado como uma das formas mais eficazes de lidar com o uso de drogas, principalmente quando se trata da utilização por jovens adolescentes. A prevenção do consumo de drogas é um caminho em que transcorrem questões emocionais dos indivíduos, por meio da abertura de canais de comunicação, aprendizagem e participação (ARATANGY, 1998; CAVALCANTE et al., 2008). Acredita-se que o uso de instrumentos de aprendizagem, muitas vezes, materiais digitais, projetados por designers podem aperfeiçoar a compreensão e auxiliar na aprendizagem. Assim, chama-se atenção, para estudos relacionados à Educação para a Saúde com outras temáticas, como por exemplo, a Saúde da Mulher para o uso da animação como importante e eficiente ferramenta de aprendizagem. (COSCARELLI, 2004; SILVEIRA et al., 2012).

A abordagem de educação para a saúde voltada para jovens e adolescentes requer proposições criativas e interessantes no uso de ferramentas audiovisuais, que estejam em linguagem e diagramação estimulantes. Essa perspectiva pode ser ofertada por meio das ferramentas do design que atuam com um olhar cuidadoso no usuário, principalmente por meio da possibilidade de utilização de animações destinada a esse público.

A abordagem das narrativas audiovisuais tem efetivo potencial educativo. As animações têm 
se configurado como recursos promissores nos processos de ensino e aprendizagem, conforme Mendes (2018), entre outros autores que apontam a eficácia do uso de narrativas audiovisuais na educação em sala de aula. Podem-se observar os mesmos benefícios na educação para a saúde.

\section{Fundamentação teórica}

A adolescência é um período complexo para os jovens. As mudanças físicas, ocasionadas por alterações hormonais, embora sigam certa sequência, apresentam variações individuais que podem provocar insegurança nos jovens, principalmente nos jovens com desenvolvimento tardio, em relação ao grupo. A diferença de desenvolvimento físico e intelectual pode gerar conflitos com adultos, já que se espera de um jovem com características físicas maduras, uma maturidade psicológica que não acompanha a aparência madura. O mesmo ocorre com meninos que amadurecem lentamente, em que é esperado um comportamento mais infantil do que o produzido pelo jovem, conforme sua maturidade psicológica, podendo ocasionar tensões com os adultos. (PALÁCIOS, 2004)

As pressões familiares, escolares, sociais em geral, podem pesar sobre o indivíduo com personalidade ainda em formação. Há ainda, neste período da vida, a necessidade de pertencimento e identificação com um grupo. Considerando sua vulnerabilidade psicológica - o indivíduo ainda não formou suas bases éticas de caráter podendo ser influenciável pelo comportamento do grupo.

No entanto, muitos adolescentes apresentam uma transição tranquila e saudável, enquanto outros apresentam dificuldades intermitentes e situacionais. Esses dados podem ser muito variáveis conforme o contexto social. Palácios (2004) considera que não é possível falar de apenas uma adolescência, melhor seria falar de adolescentes (dos diferentes tipos de adolescentes), ao invés de adolescência. A adolescência, tal como outras fases da vida, apresenta seus próprios problemas. "Convém destacar que dependerá da maneira como as coisas se apresentam, para muitos adolescentes, em nosso meio cultural" (PALÁCIOS, 2004, p. 269). O autor alerta que o caráter mais ou menos conflitivo do jovem não deve ser pensado como um conflito existente apenas nele, mas também crises e conflitos dos pais podem repercutir no jovem. Os conflitos podem ser também extrafamiliares, alheios ao jovem, mas que nele repercutem.

Neste contexto, pensar a situação de vulnerabilidade, é pensar os diferentes possíveis contextos familiares e extrafamiliares que podem contribuir para proporcionar uma adolescência mais ou menos conflituosa, problemática, situação que vai resvalar diretamente na possibilidade do contato com as drogas.

Assim, o adolescente busca a imagem de adulto independente no grupo de amigos no qual está inserido, o que acarreta em várias situações características desta fase, tais como: o pico de conflitos familiares e a perda parcial do poder de controle - dos pais sobre os filhos. É nesse período de crise que comumente as drogas se inserem em suas vidas, (CAVALCANTE et al., 2008).

Para a legislação brasileira, no artigo 10 da Lei no 11.343/2006, que cria o Sistema Nacional de Políticas Sobre Drogas - SISNAD, drogas são "substâncias ou produtos capazes de causar dependência". A Organização Mundial de Saúde - OMS (1995) já havia definido anteriormente o termo droga como toda e qualquer substância não produzida pelo organismo, com propriedade de atuar sobre um ou mais de seus sistemas, provocando alterações em seu funcionamento e podendo 
assim desencadear dependência química.

Considerando que há grande chance de os jovens terem contato com as drogas no período da adolescência, há que considerar condições agravantes tais como: pobreza, vulnerabilidade social, difícil acesso às políticas públicas inclusivas ou outros fatores. Diante destes contextos culturais e sociais, é preciso realizar trabalho preventivo junto aos jovens. O contato com as drogas nessa fase sensível da vida pode sentenciar o jovem a ser um constante usuário já que as drogas possuem grande potencial de causar dependência.

Na relação com o mundo adulto, neste período transitório, o jovem se vê envolto em questionamentos e ambivalências, podendo confundir-se e confundir os que o cercam a respeito dos limites da "normalidade" (FEIJÓ; CHAVES, 2002).

Por meio da abertura de canais de comunicação, aprendizagem e participação, a prevenção às drogas tem se mostrado o mais eficaz e eficiente caminho para este fim, abordando questões emocionais do indivíduo (ARATANGY, 1998).

Focando a aprendizagem, a utilização de atividades lúdicas como mediadoras neste processo, mostram-se ferramentas de grande importância, pois estimulam a prazerosa compreensão do assunto bem como a reflexão sobre o conhecimento adquirido e a formação de relações entre o conhecimento proporcionado pelo lúdico e a realidade vivenciada, que engloba os aspectos comportamentais individuais e coletivos (COSCRATO et al., 2010).

O processo de ensino-aprendizagem é fortalecido pela associação do lúdico às realidades, pois neste tipo de atividade o indivíduo torna-se sujeito e ator do processo educativo, desenvolvendo-se cognitiva, social e até fisicamente (GOMES et al., 2012). Apesar de a palavra "lúdico" vir do latim ludus, que significa jogo, a educação lúdica transcende a concepção ingênua de brincadeira vulgar ou diversão superficial, auxiliando no desenvolvimento do pensamento individual em permutações com o pensamento coletivo (ALMEIDA, 2003).

O uso de vídeo junto aos alunos tem impacto maior que o uso de livros ou exposição por permitir a associação da atividade educacional proposta ao conceito de entretenimento que exerce função lúdica, informativa, motivadora, entre outras (MARCELINO JÚNIOR, 2004). Barbosa (2012) acrescenta que as novas tecnologias no ambiente de ensino trazem novas perspectivas e expectativas, já que o interesse pelo aprendizado é despertado e estimulado de forma significativa, demonstrando grande potencial para a melhoria do atual panorama da educação na escola de modo acessível, compreensível e estimulante.

O avanço das tecnologias da informação e comunicação requereu dos professores o uso dos tipos de mídias existentes para tornar o ambiente de sala de aula mais dinâmico e atrativo, principalmente quando se trata de temas transversais. As mídias mais comuns em escola públicas são a TV, o vídeo e a mídia impressa. O recurso audiovisual potencializa o aprendizado, em especial se conciliado com um debate sobre o assunto, pois ativa de forma eficaz o senso crítico e reflexivo do aluno (LIMA; FREITAS, 2011).

O desenho animado possui uma significativa dimensão educativa, em especial no aspecto ativo dos valores que podem ser construídos por meio da interação. Porém, é importante ressaltar que este tipo de ferramenta não se relaciona à pedagogia diretiva, onde se trazem valores e modelos determinados para serem copiados pela criança a fim de modelar sua conduta (SILVA JÚNIOR; TREVISOL, 2009). Pelo contrário, dentre os recursos lúdicos, o desenho animado representa 
um recurso atrativo e com um contexto a ser analisado e refletido (MENDONÇA et al., 2013).

Assim, neste projeto, o recurso utilizado para servir de veículo de informação para o público será um curta-metragem de animação. Entende-se como desenho animado, termo popular para animação, segundo Aumont e Marie (2006) as formas de cinema nas quais o movimento aparente é produzido de maneira diferente da tomada de cena analógica e tem como principal técnica, a chamada animação tradicional, normalmente destinada ao público infantil. Em relação ao termo curta-metragem, entende-se como curta-metragem, obra cinematográfica ou videofonográfica de até quinze minutos, conforme legislação brasileira, constante na MP $\mathrm{n}=2.228-1$, de setembro de 2001, no artigo 1으, item VII.

\section{Desenvolvimento}

A primeira etapa consistiu em uma visita à em uma escola da rede municipal da cidade de Contagem, no estado de Minas Gerais, que ocorreu durante, aproximadamente, duas horas com um grupo focal formado por oito jovens de nove a doze anos, para obter informações sobre o universo cultural compartilhado, usando um questionário sobre preferências acerca de estilos musicais, programas de televisão, sites, revistas e produtos, a fim de conhecer os valores sociais e o meio em que este grupo está inserido.

Foi constatada uma grande divergência de referências culturais dentro do grupo, mas foi possível definir um elemento reconhecível a todos os participantes do grupo: o tomate, um alimento comum da culinária brasileira, reconhecível e familiar a todos os jovens presentes.

Definidos os elementos que serão utilizados, iniciou-se o processo de desenvolvimento da animação seguindo o método de produção audiovisual. Há algumas divergências entre os autores sobre alguns termos adotados, mas a sequência é mais ou menos a mesma. A sequência de operações sucessivas na produção audiovisual, supõe os passos: ideia; story-line, a descrição da ideia em poucas linhas; sinopse, a narrativa escrita em duas páginas; tratamento: descreve situações narrativas em cinco a oito páginas; estrutura, que fragmenta a narrativa em cenas e sequências, decide a distribuição e ordenamento, ficha relações e pauta as transições. Já Rey (2010) postula que após a ideia, parte-se para a story-line, um resumo da história em até seis linhas. Em seguida passase para o argumento, que é como um conto, mas objetivo e preso aos fatos. Será utilizada a referência da proposta de etapas de Comparato (2009), partindo da ideia, seguindo para o conflito, personagens, ação dramática, tempo dramático e unidade dramática, onde desenvolve-se o argumento e, então, o storyboard, ferramenta importante por se tratar, especialmente, de animação.

O storyboard é "uma ferramenta projetada para dar a você uma programação organizada de seu plano de filmagem frame por frame, tomada a tomada" (HART, 1999, p.4). O autor explica que se utilizam da ferramenta do storyboard para projetar e, então, produzir animações ou outros produtos audiovisuais. O storyboard é uma disposição de elementos visuais que representam, no tempo, a narrativa, trazendo características e linguagem do desenho e das histórias em quadrinhos (HQs).

Com o tema "educação para a saúde: drogas", elaborado de forma lúdica, o enredo desta animação conta a história de dois tomates que, em um galpão de armazenamento de alimentos, caíram acidentalmente de um engradado e buscam voltar para lá. Porém, no caminho, durante a busca do engradado, um dos tomates se desespera, se separa do outro e acaba conhecendo um trio 
formado por um pepino, um jiló e um abacaxi que, apresentam ao tomate, uma substância química que provoca o aceleramento do amadurecimento de frutas e legumes, o CaC2. O tomate faz uso da substância e obtém, a princípio, um resultado positivo, embora após o abuso da substância, acaba contraindo resultados negativos, como a supermaturação do vegetal, alucinações e perda de controle de seus atos. Após o tomate sentir os efeitos negativos do uso da substância, ele reencontra o outro tomate, que continua fisicamente idêntico ao que era no início da história. Juntos, eles conseguem concluir sua jornada encontrando e se realocando no engradado. $O$ desfecho se dá com um humano encontrando o engradado e retirando o tomate danificado de lá.

Por meio desde enredo, procurou-se fazer associações de situações comuns que permeiam o mundo das drogas e trazer para a realidade dos vegetais na história: o trio formado pelo pepino, o jiló e o abacaxi representa os fornecedores de drogas, enquanto a fórmula CaC2 representa a droga. A supermaturação de um dos tomates através do abuso de $\mathrm{CaC} 2$ representa os efeitos físicos que $o$ abuso de substancias químicas pode ocasionar. Estas associações foram feitas para que se percebesse o tema da animação sem tornar a intenção explícita.

Antes da animação propriamente dita, desenvolveu-se o storyboard, que é a etapa anterior à produção da animação. Conforme Cautela (2007) um storyboard está dentro da fase projetual de análise, quando identifica-se o contexto do problema de design, e assim, junta-se a fase de proposição do projeto com a sugestão de ideias e respostas. É a representação em forma de quadros de cada cena que, além de resumir de forma gráfica o enredo da história, serve para definir os enquadramentos, movimento de câmera e avaliar se a cena pode ser compreendida através das imagens pré-determinadas. Embaixo de cada quadro pode-se incluir um trecho do roteiro, ruídos ou efeitos (COMPARATO, 2009).

Figura 1 - Primeira página do Storyboard

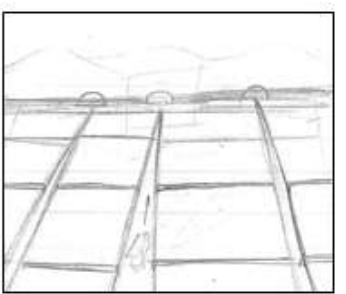

Câmera fecha em galpão central

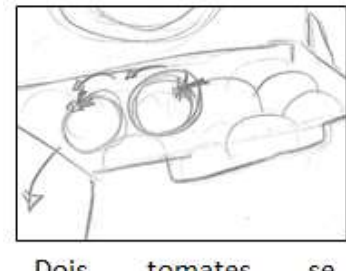
desequilibram, rolam e caem.
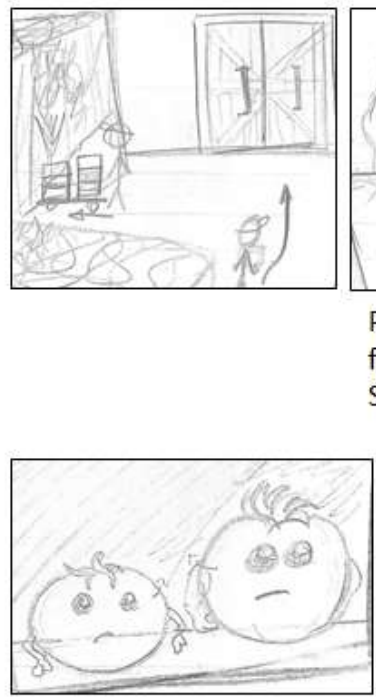

Os tomates ganham vida. Aparecem olhos e boca. Talvez braços.
Porta se abre e um

funcionário entra.

Sem mostrar o rosto
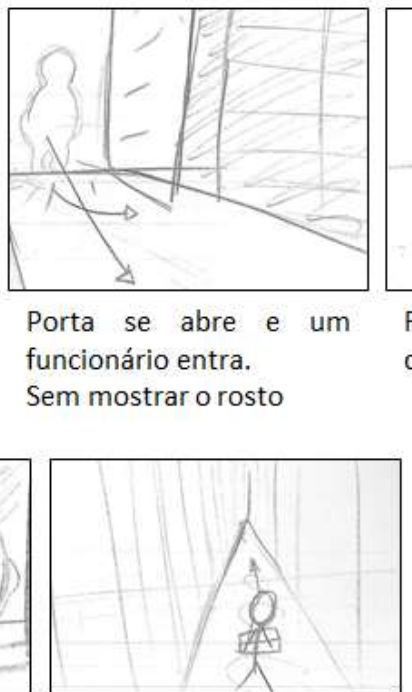

Funcionário de distancia, seguindo no corredor

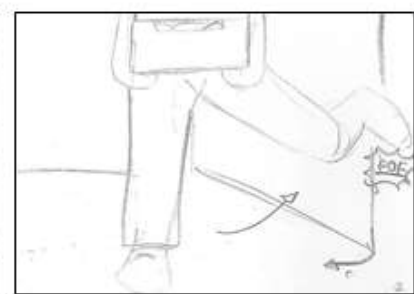

Fecha aporta com o pé, desleixadamente.

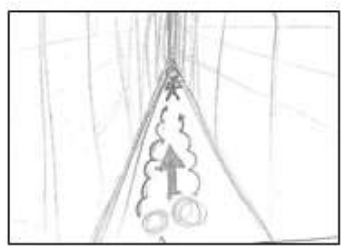

Mesmo enquadramento. Ao correr, os tomates pulam.

Fonte: Autoria própria. 
O tipo de técnica empregada nesta animação foi o Stop Motion em recortes de papel, a fim de viabilizar e agilizar a etapa de produção. A técnica Stop Motion é a mais antiga técnica de animação e onde se cria a ilusão de movimento por meio de gravação, quadro a quadro e da manipulação de um objeto ou imagem em um cenário físico espacial. Assim, com esta técnica o animador manipula um objeto concreto, que reage a luz e à profundidade de forma espontânea, o que confere às personagens uma existência convincente dentro deste contexto, acrescentando credibilidade à narrativa ali apresentada (PURVES, 2011). $O$ animador torna-se diretor e ator, que por meio de suas mãos torna o personagem crível (SHAW, 2012).

Foi montado um estúdio nas dependências da Escola de Design da Universidade do Estado de Minas Gerais, no qual foi colocada a iluminação necessária para a produção da animação e uma mesa com suporte para a câmera fotográfica de modo que a câmera fotografasse os objetos dispostos em cima da mesa. Com esta etapa finalizada, começou-se a montar os cenários e fotografar as cenas em cada um deles. As fotos são tiradas em sequência para gerar a ilusão de movimento, quadro a quadro, em um movimento linear de gravação, que também é conhecido como animação straight-ahead (PURVES, 2011).

Após todas as cenas serem fotografadas, quadro a quadro, as fotos começaram a ser tratadas através de programas de edição de imagem a fim de homogeneizá-las e adicionar a cada personagem as expressões necessárias para se comunicar. Logo depois, passou-se a montagem das cenas em um programa de edição, onde são colocadas as imagens na sua sequência correta, adicionados efeitos sonoros e convertida em formato de vídeo. Após a conversão, a animação estava pronta para ser utilizada na segunda etapa.

Na segunda etapa, foi realizada visita à mesma escola, sendo oito alunos chamados para compor um grupo focal, entre eles, quatro meninas e quatro meninos.

A primeira parte da conversa foi acerca do tema drogas: o que eles sabiam sobre o assunto. A maioria do grupo já participou de palestras ministradas em escolas públicas pelo projeto da Polícia Militar, pelo Proerd (Programa Educacional de Resistência às Drogas). Estas palestras, como se percebeu no grupo focal, foram de suma importância para formar a opinião dos estudantes sobre o assunto, pois a maior parte do conhecimento do grupo acerca do tema provinha dessas palestras, conforme informado pelos jovens. Outra fonte de conhecimento sobre o assunto foi a própria experiência dos jovens, pois alguns integrantes do grupo conhecem pessoas que fazem uso de drogas ilícitas, e sabem distingui-las pelo seu modo de uso e seus efeitos.

Após esta primeira conversa, o vídeo produzido foi apresentado. O grupo assistiu com atenção. Uma das reações mais intensas, com risos, foi no momento da história em que os tomates ficavam sob efeito das drogas. Após a conclusão da narrativa, o grupo se mostrou confuso sobre o destino do personagem protagonista. O grupo começou a comentar o vídeo espontaneamente, após a projeção. Os jovens perceberam as representações, fazendo associações naturalmente. Perceberam que os legumes representavam pessoas e a substância CaC2 representava as drogas. Os jovens fizeram comparações entre os efeitos apresentados na animação com os efeitos da maconha, um alucinógeno amplamente conhecido.

A maioria dos jovens não entendeu o motivo do personagem protagonista ter sido tirado do engradado, que era o que ele mais buscou durante sua jornada, mostrando ter criado empatia com o personagem. $O$ grupo também percebeu haver uma personificação do tomate - atribuíram a um ser inanimado, ações e sentimentos. Para além das associações lúdicas, pensando o protagonista 
como vegetal, argumentaram que um tomate ruim não pode ficar no mesmo engradado que tomates em bom estado: "O homem vai levar os tomates pra vender. Ninguém compra tomate podre" concluiu um dos estudantes. Acabaram percebendo que haviam se apegado ao personagem protagonista, por conhecerem sua história, e por isso, não concordaram de imediato com o destino deste personagem no fim da história.

Para encerrar o grupo focal, foi perguntado se aprenderam algo com o vídeo e o que seria o aprendizado obtido. A resposta foi unânime: todo o grupo concordou que a animação apresentada reforçou a ideia de que drogas são prejudiciais à saúde.

\section{Considerações finais}

Percebeu-se que a animação se mostra sim uma ferramenta de grande importância enquanto recurso pedagógico, pois ela transmite a informação de forma indireta, lúdica, com sutileza e leveza. Apresenta o contexto de modo que seja analisado pelo espectador de forma não impositiva. Além disso, as animações são parte do universo cultural dos jovens, estan do presente em momentos de lazer, o que acrescenta à atividade pedagógica uma característica de descontração, que contribui para prender a atenção do aluno com maior eficácia e naturalidade.

Percebeu-se também que as palestras ministradas pelo projeto da Polícia Militar, o Proerd, foram relevantes para os resultados do experimento, pois o grupo já tinha uma base de informações que os ajudou a compreender mais facilmente as associações propostas pelo enredo da animação, incluindo a identificação de comportamentos de personagens e das situações mostradas na história com situações reais.

Percebeu-se que o recurso audiovisual, em especial a animação, se mostrou como uma eficiente e atraente ferramenta para utilização a serviço da promoção e educação para a saúde, direcionadas aos jovens pré-adolescentes.

Espera-se que este estudo possa ser útil e que desperte interesse da comunidade escolar e acadêmica para desenvolver projetos neste âmbito, utilizando a animação e demais recursos audiovisuais em favor da educação e da saúde.

\section{Referências}

ALMEIDA, P. N. Educação lúdica: técnicas e jogos pedagógicos. 11ạ edição. São Paulo: Edições Loyola, 2003.

ARATANGY, L. R. O desafio da prevenção. In: J. G. Aquino (Org.), Drogas na escola: alternativas teóricas e práticas. São Paulo: Summus Editorial, 1998.

AUMONT, J.; MARIE, M. Dicionário teórico e crítico de cinema. Campinas: Papirus, 2006.

BARBOSA, M. C. et al. Educando com design de animação: uma metodologia de ensinoaprendizagem. Infodesign, v. 9, n. 1, 2012, p. 21-33.

CAUTELA, C. Strumenti di design management. Milão: Tipomonza, 2007.

CAVALCANTE, M.; ALVES, M.; BARROSO, M. Adolescência, álcool e drogas: uma revisão na perspectiva da promoção da saúde. In: Rev. Enferm. set. 2008. Disponível em: 
<http://www.scielo.br/pdf/ean/v12n3/v12n3a24>. Acesso em: 08 out. 2014.

COSCARELLI, C. Objetos para aprender fazendo. São Paulo: Universia, 2004. Disponível em: <http://www.universia.com.br/ead/materia.jsp?materia=3025>. Acesso em: 18 out. 2016.

COSCRATO, G. et al. Utilização de atividades lúdicas na educação em saúde: uma revisão integrativa da literatura, Acta Paulista de Enfermagem, São Paulo, v. 23, n. 2, p. 257-63, 2010.

COMPARATO, D. Da criação ao roteiro. Ed. revista e atualizada, com exercícios práticos. Rio de Janeiro: Rocco, 2009.

FEIJÓ, R. B.; CHAVES, M. L. F. Comportamento suicida. In: COSTA, M. C. O. ; SOUZA, R. P. de (Orgs.). Adolescência. Porto Alegre: Artmed Editora, 2002. p. 398-408.

GOMES, M. P. et al. Desenho animado: recurso pedagógico no processo ensino-aprendizagem de educação ambiental. Encontro Nacional de Ensino de Ciências da Saúde e do Ambiente. v.3, Niterói, 2012.

HART, J. The art of the storyboard: Storyboarding for film, TV and animation. Woburn: Focal Press, 1999.

IBGE. Pesquisa Nacional de Saúde do Escolar, 2012. Disponível em: <https://biblioteca.ibge.gov.br/visualizacao/livros/liv64436.pdf> Acessado em: 20 nov. 2015

LIMA, M. D. A.; FREITAS, Antônio Francisco Ribeiro de. Uso de vídeo e da mídia impressa para o aprendizado de temas transversais, uma experiência com alunos do 8 ano de uma escola pública de Maceió. Encontro de pesquisa e Educação em Alagoas, Maceió, v. 6, 2011.

MARCELINO JÚNIOR et al. Perfumes e essências: a utilização de um vídeo na abordagem de funções orgânicas. Química Nova na Escola, 2004. p. 19, 15-18.

MENDES, M. A. A. Produção e utilização de animações e vídeos no ensino de biologia celular para a 1a série do ensino médio, 2018. Disponível em <http://repositorio.unb.br/handle/10482/9029> Acessado em 30 mar. 2018.

MENDONÇA, A. V. P. de M.; et al. Uma reflexão sobre a influência dos desenhos animados e possibilidade de utilizá-los como recurso pedagógico. 2010. Disponível e <http://portal.sipeb.com.br/santana/files/2010/08/A-influ\%C3\%AAncia-dosdesenhosanimados.pdf>. Acesso em: 17 nov. de 2015.

MINISTÉRIO DA SAÚDE (BRASIL), Secretaria de Gestão Estratégica e Participativa. II Caderno de educação popular em saúde. Brasília: Ministério da Saúde, 2014.

OMS. Organizacíon Mundial de La Salud. La salude de los jovens: un reto y una esperanza. Ginebra. 1995. 120p.

PALACIOS, J. O que é adolescência. In: César; MARCHESI, A.; PALACIOS, J. (Orgs.). Desenvolvimento psicológico e educação: Psicologia evolutiva. v.1. Porto Alegre: Artmed, 2004. p. 263-272.

PURVES, Barry. Stop Motion. Porto Alegre: Bookman, 2011. 199p.

REIS D. C. Educação em saúde aspectos históricos e conceituais. IN: Grazinelli M. F., Marques R. C., e organizadores. Educação em saúde: teoria, métodos e imaginação. Belo Horizonte: UFMG; 2006. p. 19-24. 
REY, M. O roteirista profissional: televisão e cinema. São Paulo: Ática, 2010.

SHAW, Susannah . Stop Motion: técnicas manuais para animação com modelos. 2. ed. Rio de Janeiro: Elsevier, 2012

SíCOLI, J. L., NASCIMENTO, P. R. Health promotion: concepts, principles and practice, Interface Comunic, Saúde, Educ, v.7, n.12, p.91-112, 2003.

SILVA JÚNIOR, A. G.; TREVISOL, M. T. C. Os desenhos animados como ferramenta pedagógica para o desenvolvimento da moralidade. IX Congresso Nacional de Educação - EDUCERE; III Encontro Sul Brasileiro de Psicopedagogia, 2009.

SILVEIRA, D. T. et al. Objetos educacionais digitais para a saúde da mulher. RECIIS - R. Eletr. De Com. Inf. Inov. Saúde. Rio de Janeiro, v.6, n.2, jun., 2012.

ZUGE, Samuel Spiegelberg ; BRUM, Crhis Netto de. Educação em Saúde e comunicação: a práxis da enfermagem. Revista Espaço acadêmico. Maringá, n. 106, 2010. 